\title{
Artigo/Article
}

\section{Dengue: aspectos epidemiológicos e o primeiro surto ocorrido na região do Médio Solimões, Coari, Estado do Amazonas, no período de 2008 a 2009}

\author{
Dengue: epidemiological aspects and the first outbreak in the Middle Solimões Region of \\ Coari in the State of Amazonas from 2008 to 2009
}

\begin{abstract}
Allyson Guimarães da Costa ${ }^{1}$, Jefferson Dantas dos Santos ${ }^{1}$, Jemmis Karters Tomé da Conceição ${ }^{1}$, Priscilla Heckmann Alecrim ${ }^{1}$, Almeida Andrade Casseb ${ }^{2}$, Weber Cheli Batista ${ }^{2}$ e Maria Izabel Ovellar Heckmann ${ }^{1}$

RESUMO

Introdução: A dengue é uma das doenças infecciosas mais frequentes no Brasil e um dos

\section{INTRODUÇÃO} principais problemas de saúde pública no mundo, principalmente em regiões tropicais e subtropicais, com 2,5 a 3 bilhões de pessoas expostas ao risco de serem infectadas atualmente. Deste modo, o presente estudo teve como objetivo demonstrar as características epidemiológicas dos indivíduos acometidos por dengue, sua prevalência e seu processo epidêmico na região do Médio Solimões, Coari, Amazonas, no período de 2008 e 2009. Métodos: Os dados epidemiológicos foram obtidos na Vigilância Epidemiológica da Secretaria Municipal de Saúde da Cidade de Coari-AM. As variáveis analisadas foram: mês da notificação, casos confirmados, gênero (sexo), faixa etária e bairro de residência. Resultados: No total, foram notificados 1.003 casos (635 em 2008 e 368 em 2009), sendo diagnosticados 639 casos positivos. Destes, $\pm 54 \%$ acometerem indivíduos do sexo feminino e $\pm 46 \%$ do sexo masculino. As faixas etárias mais acometidas foram às observadas entre 10-49 anos; quanto à distribuição espacial, observamos o acometimento de indivíduos de bairros próximos a igarapés, lagos e com processo recente e desordenado de habitação. Conclusões: Deste modo, conclui-se que, durante o período estudado, houve um surto epidêmico de dengue na Cidade de Coari, AM. Entretanto, deve-se considerar que uma epidemia de dengue anterior pode ter ocorrido em Coari, sem que tenha tido o devido diagnóstico etiológico, ou que houveram pessoas com infecção passada que se deslocaram para a capital do Amazonas (Manaus), onde os vírus circulam desde 1998.

Palavras-chaves: Dengue. Surto epidêmico. Coari. Amazonas.

\begin{abstract}
Introduction: Dengue is one of the most prevalent infectious diseases in Brazil and is a major public health problem worldwide. It is most prevalent in tropical and subtropical regions with 2.5 to 3 billion people at risk of becoming infected. Thus, this study sought to demonstrate the epidemiological characteristics of individuals affected by dengue, its prevalence and its epidemic process in the Middle Solimões region of Coari in the state of Amazonas between 2008 and 2009. Methods: Epidemiological data were obtained through epidemiological monitoring by the Municipal Health Facility of the city of Coari, AM. The variables analyzed were the month of notification, the number of confirmed cases, the cases' genders, the cases' ages and their neighborhoods of residence. Results: In total, 1,003 cases were reported (635 in 2008 and 368 in 2009), and 639 cases were diagnosed as positive. Of these, $\pm 54 \%$ involved female subjects, and $\pm 46 \%$ were male. The majority of the affected individuals were between 10 and 49 years of age, and the spatial distribution was concentrated in neighborhoods near streams, lakes and areas in which housing had recently been disrupted. Conclusions: We concluded that, during the period studied, there was an outbreak of dengue in the City of Coari, AM. However, it is possible that a dengue epidemic may have occurred earlier in Coari without proper diagnosis or follow-up and that previously infected individuals may have traveled to the capital of Amazonas (Manaus), where the virus has circulated since 1998.
\end{abstract}

Keywords: Dengue. Epidemic outbreak. Coari. Amazonas.

1. Instituto de Saúde e Biotecnologia, Universidade Federal do Amazonas, Coari, AM. 2. Instituto de Pesquisas em Patologias Tropicais, Fundação Oswaldo Cruz, Porto Velho, RO.

Endereço para correspondência: Dra. Maria Izabel Ovellar Heckmann. ISB/UFAM. Campus da UFAM, Estrada Coari-Mamiá 305, Espírito Santo, 69460-000 Coari, AM.

Tel: 5597 3561-2363; 8118-1939

e-mail: heckmann@ufam.edu.br

Recebido para publicação em 03/03/2010

Aceito em 25/02/2011
A dengue é uma das doenças infecciosas mais frequentes no Brasil e um dos principais problemas de saúde pública no mundo, principalmente em regiões tropicais e subtropicais. Apresenta quadro clínico de início repentino e amplo, variando desde formas oligossintomáticas (infecção inaparente) e sintomáticas (dengue clássica) até quadros graves com hemorragias (febre hemorrágica da dengue - FHD) e choque (síndrome do choque da dengue - SCD) ${ }^{1}$. Etiologicamente, seu agente causador é um vírus pertencente à família flaviviridae com genoma RNA e quatro sorotipos conhecidos (DEN-1, DEN-2, DEN-3 e DEN-4) ${ }^{2}$. Sua transmissão é feita pelo mosquito Aedes aegypti, principal vetor, que em geral utiliza recipientes artificiais para proliferação vetorial, tornando essa espécie predominantemente urbana ${ }^{3}$.

Esta arbovirose atinge a população de todos os estados brasileiros, independente da classe social. Em 2001, dos 3.567 municípios dos 27 estados brasileiros encontravam-se infestados e a transmissão já ocorria em 2.262 cidades de 24 estados destes. No ano de 2007, somente o Estado de Santa Catarina não apresentou transmissão autóctone ${ }^{4}$.

Segundo estimativas da Organização Mundial da Saúde (OMS), 80 milhões de pessoas são infectadas, anualmente, com cerca de 550 mil hospitalizações e 20 mil óbitos $^{5}$. Dessas, aproximadamente, 50 milhões encontram-se em regiões tropicais e subtropicais, levando-se em consideração que, atualmente, 2,5 a 3 bilhões de pessoas vivem expostas ao risco de serem infectadas por esta arbovirose $e^{4,6,7}$.

O Brasil apresentou a primeira epidemia no início da década de 80, onde foram isolados os sorotipos DEN-1 e DEN-4 no Estado de Roraima, com cerca de 11.000 pessoas infectadas ${ }^{8,9}$. Em seguida, foram registradas várias epidemias e surtos em diversas regiões do Brasil, como a sudeste (Rio de Janeiro, São Paulo, Minas Gerais) e a nordeste (Alagoas e Ceará), com o sorotipo DEN-1 como 
o fator causal dessas ${ }^{10}$. Na região norte, com exceção do Estado de Roraima, os casos só foram isolados, a partir de 1995. Nas Cidades de Redenção e Rondon, no Estado do Pará ${ }^{11}$, no período de 1998 a 1999; na Cidade de Manaus, no Estado do Amazonas, com 3.423 casos confirmados ${ }^{12}$, em 1999; na Cidade de Porto Velho, Estado de Rondônia, apesar de não ter havido sorotipagem do vírus causador da doença ${ }^{13} \mathrm{e}$, por fim, em outros estados da região como Acre, Amapá e Tocantins, em 1999 e $2000^{14}$.

No Estado do Amazonas, especificamente na Cidade de Manaus, ocorreram vários surtos e epidemias, sendo a primeira ocorrida no período entre 1998-1999, com 3.423 casos confirmados ${ }^{12}$ e, posteriormente, em 2001, com 18.595 casos. Ressaltando que após este período a dengue adquiriu caráter endêmico, com aumento da incidência nos períodos de chuvas ${ }^{15}$.

Em Coari, AM (Figura 1), o mosquito A. aegypti foi descrito pela primeira vez pela Fundação Nacional de Saúde (FNS), através da Gerência de Endemias e do Controle de Zoonoses, em meados de 2002 , ressaltando que até o início de 2008, a cidade não apresentava indivíduos com esta patologia, com exceção de um caso alóctone, no período de 1998-1999 ${ }^{12}$.

Deste modo, o presente estudo teve como objetivo demonstrar as características epidemiológicas dos indivíduos acometidos por dengue, sua prevalência e seu processo epidêmico na região do Médio Solimões, Coari, Estado do Amazonas, no período de 2008 e 2009 (Figura 1).

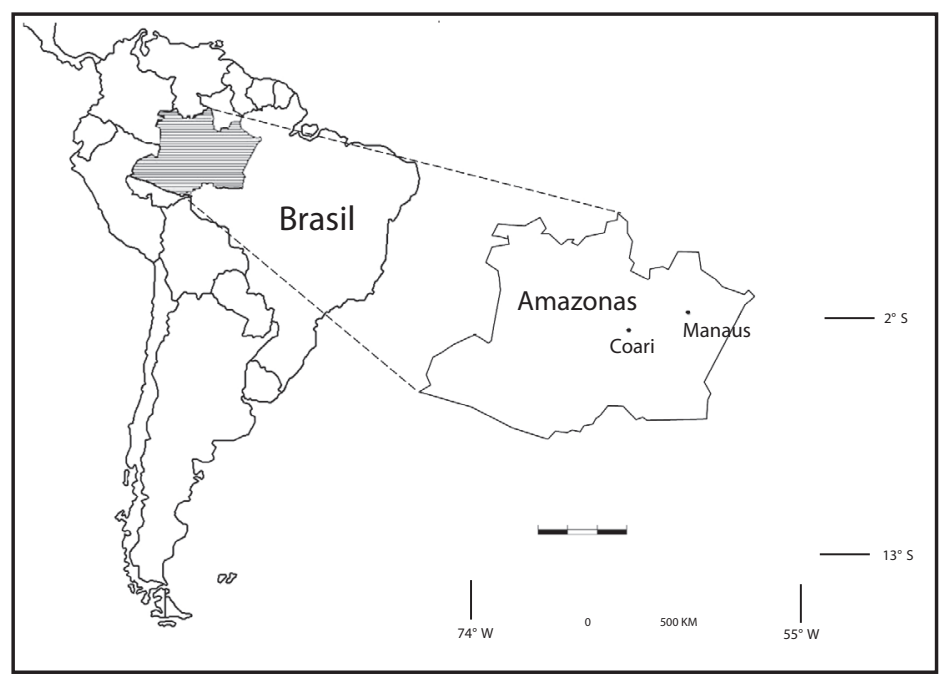

FIGURA 1 - Localização do Estado do Amazonas e da Cidade de Coari.

\section{MÉTODOS}

\section{Área de estudo}

O município de Coari (Figura 1), no Estado do Amazonas, está localizado na parte da planície Amazônica revestida de um lado pelas florestas tropicais da região e banhado por outro pelo Rio Solimões e calhas dos Lagos Coari e Mamiá. A cidade possui uma área de $57.277 .090 \mathrm{~km}^{2}$, sendo a $5^{\text {a }}$ maior cidade do Estado do Amazonas ${ }^{16}$. Distante cerca de $363 \mathrm{~km}$ de Manaus, capital do estado, com acesso por via fluvial e aérea. Possui estimativa populacional de 65.222 habitantes, sendo que deste total, 52,1\% são indivíduos do sexo feminino e $47,9 \%$ do sexo masculino, ressaltando que $67 \%$ de indivíduos residem na área urbana e 33\% na área rural, segundo dados do Instituto Brasileiro de Geografia e Estatística (IBGE) ${ }^{17}$. O clima é equatorial quente e úmido, com duas estações distintas, inverno (período chuvoso) e verão (período de seca), a temperatura média anual varia de $24^{\circ} \mathrm{C}$ e $26^{\circ} \mathrm{C}$. A cidade atualmente é umas das mais ricas da região norte em decorrência da exploração de petróleo e gás natural pela Petrobrás na bacia de Urucu.

\section{Fonte dos dados e análise}

Os dados epidemiológicos foram obtidos na Vigilância Epidemiológica da Secretaria Municipal de Saúde, da Cidade de Coari-AM, a partir das fichas de notificação do Sistema de Informação de Agravos de Notificação (SINAN). Os referidos dados foram coletados durante atendimento dos pacientes no Hospital Regional de Coari ou nas Unidades Básicas de Saúde, sendo posteriormente coletadas as amostras para a sorologia e em seguida enviadas aos centros de referência (Laboratório Central (LACEN), em Manaus, AM e Instituto Evandro Chagas (IEC), em Belém, PA), para diagnóstico através da técnica imunoenzimática (ELISA) que detecta anticorpos das classes IgM e IgG, sendo preconizado pelo Ministério da Saúde, por ser simples e rápida ${ }^{4}$. Confirmado o diagnóstico pelo teste laboratorial, as fichas notificadas foram resgatadas e assinaladas para posterior submissão no sistema online do SINAN. As variáveis obtidas e analisadas foram: mês da notificação, casos confirmados, gênero (sexo), faixa etária e bairro de residência. Os dados foram organizados e distribuídos em gráficos e tabelas para melhor comparação da evolução da doença, entre os anos de 2008 e 2009.

\section{RESULTADOS}

No ano de 2008, foram notificados 635 casos suspeitos de dengue, sendo que desses, 417 foram positivos. No ano de 2009, houve uma considerável queda nos números em relação ao mesmo período do ano anterior com 368 casos notificados e 222 casos positivos de dengue. A distribuição temporal em ambos os anos são diferentes, como pode ser observado na Figura 2, dado o início do surto epidêmico.

Quando analisamos os dados por gênero (sexo) dos casos confirmados de dengue, observamos que os indivíduos do sexo feminino representam $55,7 \%$ dos casos e do sexo masculino $44,3 \%$ no ano de 2008. Em 2009, o sexo feminino representou 52,3\% dos casos confirmados e o sexo masculino $47,7 \%$.

Quando analisado os dados por faixa etária, observamos que em 2008, o maior número de casos ocorreu em indivíduos com faixas etárias entre 10 e 49 anos. Do mesmo modo que em 2008,

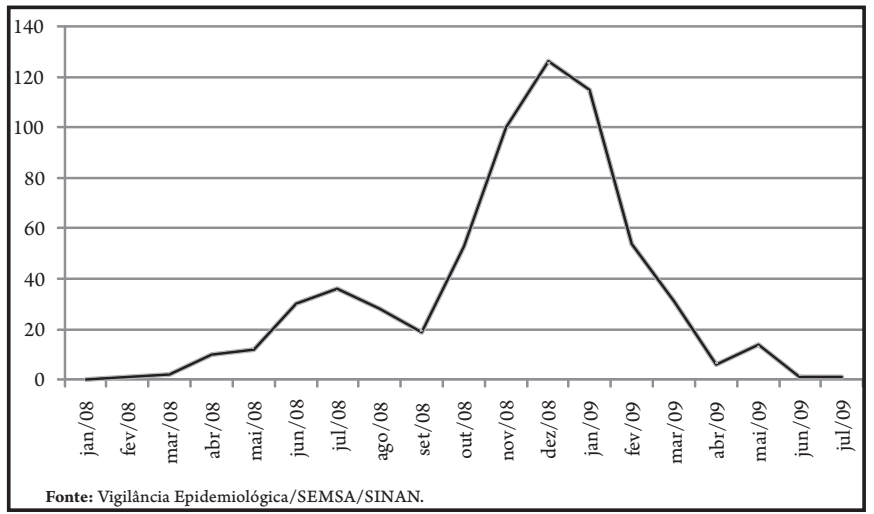

FIGURA 2 - Distribuição mensal do número de casos confirmados de dengue, Cidade de Coari, Estado do Amazonas, nos anos 2008 e 2009. 
no ano de 2009 observamos o maior número de casos nessas mesmas faixas etárias (Figura 3).

Foram analisados ainda a distribuição espacial dos casos confirmados de dengue, onde observou-se que dos 11 bairros existentes, os bairros Urucu, Tauá-Mirim, Espírito Santo, Duque de Caxias, União e Centro apresentaram os maiores índices de incidência no ano de 2008. Em 2009, os bairros mais atingidos foram Espírito Santo, Tauá-Mirim, Duque de Caxias, Chagas Aguiar, Itamaraty e Centro (Figura 4).

Por fim, observou-se que tanto no ano de 2008, quanto no ano de 2009, foram notificados clinicamente e considerados diagnósticos através da presença de plaquetopenia os casos com formas graves da dengue, variando desde a dengue com complicações (DCC) e febre hemorrágica da dengue (FHD) até a síndrome do choque da dengue (SCD). No ano de 2008, foram notificados 7 casos de DCC, sendo 5 destes em indivíduos do sexo feminino e 2 do sexo masculino, 3 casos de SCD, sendo 2 em indivíduos do sexo feminino e 1 do sexo masculino e apenas 1 indivíduo do sexo masculino com FHD. No ano de 2009, os casos com complicações limitam-se apenas a um caso de DCC em paciente do sexo feminino.

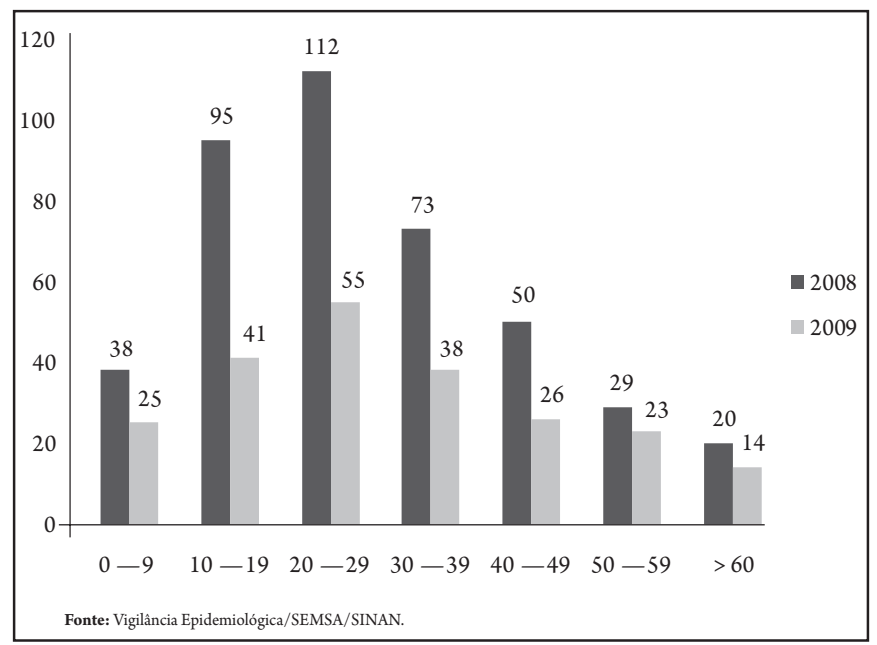

FIGURA 3 - Distribuição dos casos confirmados de dengue por faixa etária, nos anos 2008 e 2009.

\section{DISCUSSÃo}

Após a detecção do mosquito Aedes aegypti na Cidade de Coari, em meados de 2002, observa-se um intervalo significante até a notificação e confirmação do primeiro caso de dengue no início de 2008 em um indivíduo residente no bairro Duque de Caxias. Contudo, não se pode descartar o fato da infecção pelo vírus da dengue ocasionar uma variedade de sintomas clássicos e facilmente confundíveis com outras patologias febris e exantemáticas, como malária ${ }^{12}$. Assim, o número de casos pode ser duplicado ou triplicado, visto que esses não foram notificados e ou confundidos com outras doenças. Com intuito de descartar um possível diagnóstico de malária, rotineiramente, o exame de gota espessa é indicado aos pacientes com suspeita de dengue, os quais são encaminhados ao Núcleo de Medicina Tropical da Cidade de Coari, AM para confirmação ou exclusão de malária.

Anteriormente ao período de 2008, o sistema de notificação de casos de dengue na Cidade de Coari, não era realizado pelo Hospital Regional e Unidades Básicas ou pela Vigilância Epidemiológica da Secretaria Municipal de Saúde. Posteriormente, com o aparecimento de casos de dengue, no início de 2008, os casos suspeitos foram notificados e amostras sorológicas foram enviadas ao Laboratório Central (LACEN), em Manaus, AM e ao Instituto Evandro Chagas, em Belém-PA (centros de referências), para diagnóstico laboratorial. Entretanto, apenas os resultados das sorologias para dengue (ELISA) são disponibilizados. Uma vez que não foram realizados testes moleculares ou isolamento viral, não permitindo assim descrever os sorotipos circulantes durante esse surto.

Quando observada a incidência da doença nos anos de 2008 e 2009 , percebe-se que no primeiro ano, período do surto epidêmico na cidade, o padrão de sazonalidade não acompanhou o representado na região e no restante do país, o qual indica que os cinco primeiros meses do ano correspondem ao período mais quente e úmido, típico para proliferação do mosquito e aumento de casos de dengue ${ }^{12,18}$.

Ao analisar a distribuição percentual, por sexo, dos indivíduos acometidos com dengue, percebeu-se que os indivíduos do sexo feminino foram mais acometidos nos dois anos do estudo, gênero esse que apresentou em sua maioria a doença com complicações e

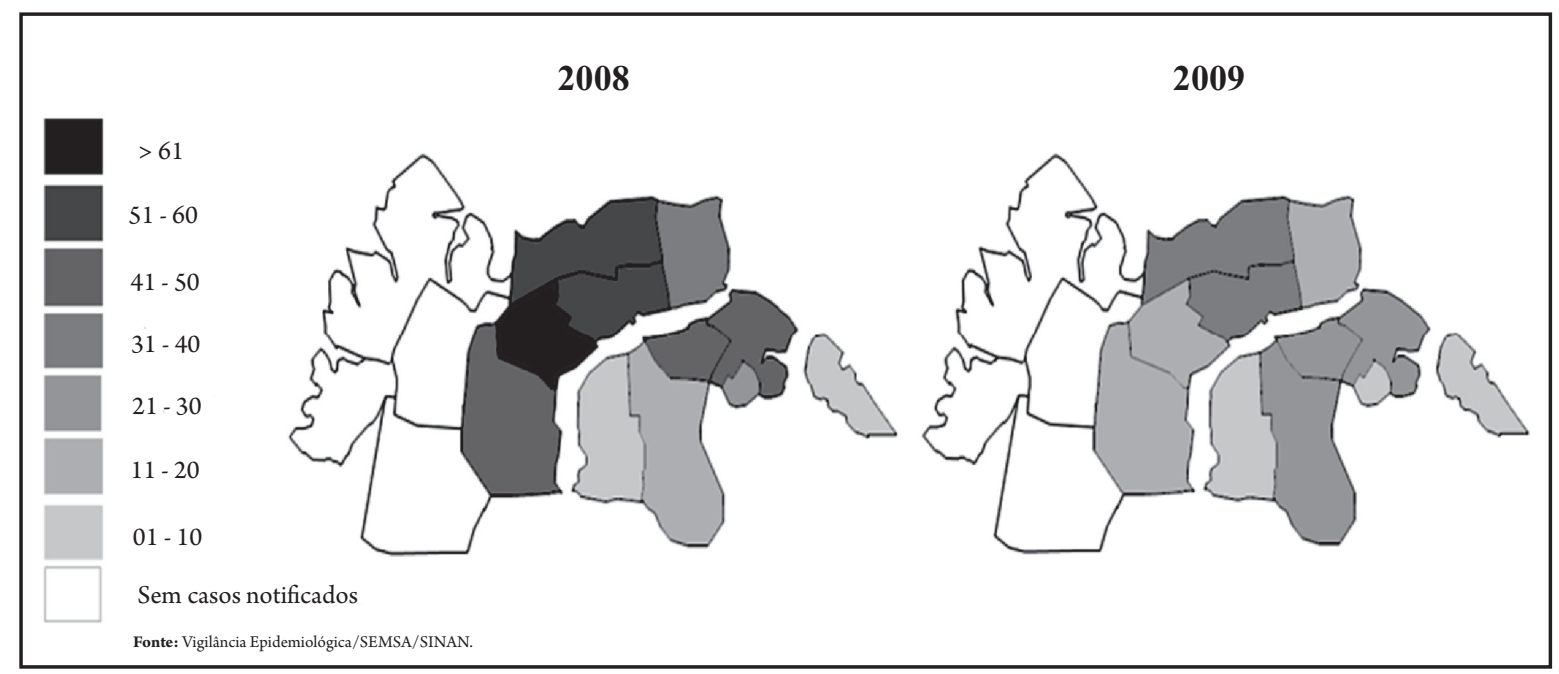

FIGURA 4 - Distribuição espacial do número de casos confirmados de dengue notificados pela Secretaria Municipal de Saúde, bairros do Município de Coari, Estado do Amazonas nos anos de 2008 e 2009. 
choque. Quanto à faixa etária, os indivíduos economicamente ativos (faixa etária entre 10 e 49 anos) foram mais acometidos pela doença. O mesmo resultado foi observado na primeira epidemia de dengue em Manaus no período de 1998-1999 12 e no Estado do Pará em 1999, onde os grupos mais vulneráveis foram os economicamente ativos ${ }^{19}$.

Quanto à distribuição espacial da dengue na cidade, observa-se que os bairros mais afetados foram aqueles que têm sua localização próxima a igarapés, lagos e com processo recente e desordenado de habitação. Segundo a Organização Pan-Americana de Saúde (OPAS), existem fatores contribuintes para o aumento dos casos de dengue, como: coleta de lixo deficiente, densidade populacional alta, habitações sem água encanada e com recipientes inadequados de armazenamento e condições sócio-econômicas precárias ${ }^{20}$. Esses fatores podem ter contribuído para a proliferação do vetor e desse modo disseminar a doença. Sendo um fator de risco para a infecção, morar em locais onde estejam ocorrendo elevado número de casos, levando em consideração outros fatores que podem representar risco como faixa etária e sexo ${ }^{11}$.

Vale ressaltar que a cidade possui aeroporto e porto hidroviário, os quais recebem diariamente indivíduos de outras cidades, além de indivíduos de outras nacionalidades, pois o Amazonas possui extensa fronteira com países como Colômbia, Peru e Venezuela. Desse modo, torna-se possível a importação de novos sorotipos da dengue e seu principal vetor, considerando ainda que os porões das embarcações típicas da região Amazônica são propícios ao transporte destes vetores para outras cidades. Outro ponto a ser considerado é a entrada de grande fluxo de migrante na Cidade de Coari, no período entre 2006 e 2007, ocasionado pelas obras do gasoduto Coari-Manaus da Petrobrás, onde estima-se que vieram para esta região indivíduos de todos os estados do país, inclusive de áreas endêmicas dessa doença.

Deste modo, conclui-se que, durante o período estudado, houve um surto epidêmico de dengue na Cidade de Coari, AM e verificouse que não há diferenças significativas, quanto aos números de casos positivos por sexo, que as faixas etárias mais atingidas compreendem os intervalos de 10 a 49 anos e que os bairros com maiores números de casos foram os localizados próximos a igarapés, lagos e em processo de habitação recente e desordenada. Entretanto, deve-se considerar que uma epidemia de dengue anterior pode ter ocorrido em Coari, sem que tenha tido o devido diagnóstico etiológico, ou houve pessoas com infecção passada que se deslocaram para a capital do Amazonas (Manaus), onde os vírus circulam, desde 1998. Ressaltando que a melhor maneira de controlar o aumento de casos de dengue é combatendo os criadouros dos mosquitos, através de campanhas de eliminação de criadouros e conscientização da população das áreas afetadas e de risco, vez que não há até o presente momento nenhuma vacina ou medicamento especifico para a doença.

\section{AGRADECIMENTOS}

Vigilância Epidemiológica da SEMSA de Coari, na pessoa do Enf. Jefferson L. da Cunha pela disponibilização dos dados.

\section{CONFLITO DE INTERESSE}

Os autores declaram não haver nenhum tipo de conflito de interesse no desenvolvimento do estudo.

\section{SUPORTE FINANCEIRO}

Conselho Nacional de Desenvolvimento Científico e Tecnológico (CNPq) e Fundação de Amparo à Pesquisa do Estado do Amazonas (FAPEAM)/Bolsa de IC.

\section{REFERÊNCIAS}

1. Ministério da Saúde. Secretária de Vigilância em Saúde. Departamento de Vigilância Epidemiológica. Doenças Infecciosas e Parasitarias: Guia de Bolso. 7a ed. rev. Brasília: Ministério da Saúde; 2008.

2. Organização Mundial de Saúde. Dengue Hemorrágica: diagnóstico, tratamento, prevenção e controle. São Paulo: Editora Santos; 2001.

3. Forattini OP. Culicidologia Médica: identificação, biologia e epidemiologia. Vol. 2. São Paulo: Edusp; 2002.

4. Tauil PL. Aspectos críticos do controle do dengue no Brasil. Cad Saude Publica 2002; 18: 867-871.

5. Ministério da Saúde. Secretaria de Atenção à Saúde. Departamento de Atenção Básica. Caderno de Atenção Básica. Vigilância em Saúde: Dengue, Esquistossomose, Hanseníase, Malária, Tracoma e Tuberculose. 2a ed. rev. Brasília: Ministério da Saúde; 2008.

6. Nogueira MB, Stella V, Bordignon J, Batista WC, Borba L, Pereira-da-Silva LH, et al. Evidence for the co-circulation of dengue vírus type 3 genotypes III and $\mathrm{V}$ in the Northern region of Brazil during the 2002-2004 epidemics. Mem Inst Oswaldo Cruz 2008; 103:482-488.

7. Sistema de Informações de Agravos de Notificação [Internet]. Secretaria Municipal de Saúde de Manaus, Estado do Amazonas. 2007 - [acesso em 13 de novembro de 2009]. Disponível em: http://dtr2004.saude.gov.br/sinanweb/.

8. Osanai CH, Rosa APAT, Tang AT, Amaral RS, Passos AC, Tauil PL. Surto de Dengue em Boa Vista, Roraima. Rev Inst Med Trop Sao Paulo 1983; 25:53-54.

9. Rosa APAT, Rocha JM, Silva OV, Lins ZC. Surto de Dengue em Boa Vista, território de Roraima, Brasil. Boletim Epidemiológico 1982; 14:93-100.

10. Rosa APAT, Vasconcelos PFC, Pinheiro FP, Rosa JFST, Rodrigues SG. Dengue. In: Leão RNQ coordenador. Doenças Infecciosas e Parasitárias: Enfoque Amazônico. Belém: CEJUP/Universidade do Estado do Pará; 1997. p. 227-248.

11. Instituto Evandro Chagas. Doenças Infecciosas e Parasitárias: Enfoque Amazônico. Belém: CEJUP/Universidade do Estado do Pará; 1997.

12. Figueiredo RMP, Thatcher BD, Lima ML, Almeida TC, Alecrim WD, Guerra MVF. Doenças Exantemáticas e primeira epidemia de dengue ocorrida em Manaus, Amazonas, no período de 1998-1999. Rev Soc Bras Med Trop 2004; 37:476-479.

13. Vieira DS, Honda ER, Pereira SS, Bifano GS, Tada MS, Batista WC. Caracterization of dengue virus serotype 1 in epidemics in Porto Velho, Rondônia, in 2001-2003. Rev Soc Bras Med Trop 2007; 40:268-271.

14. Fundação Nacional de Saúde. Boletim Epidemiológico. Brasília: Ministério da Saúde; 2000.

15. Rocha LA, Tauil PL. Dengue em crianças: aspectos clínicos e epidemiológicos, Manaus, Estado do Amazonas, no período de 2006 e 2007. Rev Soc Bras Med Trop 2009; 42:18-22.

16. Instituto Brasileiro de Geografia e Estatística. Histórico da Cidade de Coari [Internet]. Ministério do Planejamento, Orçamento e Gestão. [acesso 23 maio 2009]. Disponível em: http://www.ibge.gov.br/cidadesat/historicos_cidades/ historico_conteudo.php?codmun=130120/.

17. Instituto Brasileiro de Geografia e Estatística. Censo 2007 [Internet]. Ministério do Planejamento, Orçamento e Gestão. [acesso 22 maio 2009]. Disponível em: http://www.ibge.gov.br/cidadesat/default.php/.

18. Câmara FP, Theophilo RLG, Santos GT, Pereira RFG, Câmara DCP, Matos RRC. Estudo retrospectivo (histórico) da dengue no Brasil: características regionais e dinâmicas. Rev Soc Bras Med Trop 2007; 40:192-196.

19. Araújo TP, Rodrigues SG, Costa MIWA, Vasconcelos PFC, Travassos-da-Rosa APA. Diagnóstico sorológico de infecções por dengue e febre amarela em casos suspeitos no Estado do Pará, Brasil, 1999. Rev Soc Bras Med Trop 2002; 36:579-584.

20. Organização Pan-Americana de Saúde. Diretrizes relativas à prevenção e ao controle da dengue e da dengue hemorrágica nas Américas. Relatório de Reunião sobre Diretrizes para a Dengue. Washington: Organização Pan-Americana de Saúde; 1991. 